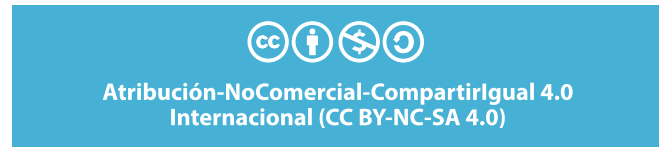

DOI: http://dx.doi.org/10.20983/reij.2021.2.7
Dirceu Ismael Solís Mendoza ${ }^{1}$

FECHA DE RECEPCIÓN: 03 de diciembre 2020

FECHA DE ACEPTACIÓN: 10 de febrero 2021

\title{
UNA MUESTRA DE LA POSTURA EN LA FRONTERA DE CIUDAD JUÁREZ ANTE EL MATRIMONIO IGUALITARIO
}

\author{
A Sample of the Position on the Border of Ciudad Juarez before Equal Marriage
}

\section{Resumen}

El presente trabajo tuvo la finalidad de analizar la percepción de una muestra de la sociedad en Ciudad Juárez con respecto al prejuicio hacia personas homosexuales y al matrimonio igualitario; puesto que, si bien esta postura no infiere directamente en la creación de leyes que impulsen o frenen la normatividad de estas figuras jurídicas, no debe de pasarse por alto que las personas que provienen de partidos políticos y que conforman los Congresos Federales y Estatales son los que, mediante posturas ideológicas y en ocasiones promesas de campaña, sí tienen el poder para influir en la aprobación de estas leyes. Al estudiar la postura tomada por la población, se pudo determinar cuáles son los principales argumentos en contra del matrimonio igualitario y qué políticas públicas se pueden llevar a cabo para generar un avance progresivo de la opinión de la ciudadanía, que permita seleccionar candidatos con fundamentos prohumanistas. Para esclarecer lo anterior, se realizó un análisis evolutivo del matrimonio a nivel nacional e internacional, retomando estudios de Cabrera Priego, Calvo Caravaca, Salina Hernández, entre otros; posteriormente, se realizó una investigación cuantitativa, no experimental, transversal y descriptiva, con una muestra no probabilística por conveniencia de 150 personas, a los que se les aplicó un cuestionario con 36 ítems

Palabras clave: matrimonio igualitario, grupos disidentes, prejuicio, homosexuales

\section{Abstract:}

The present work had the purpose of analyzing the perception of a sample of the society in Ciudad Juarez, regarding the prejudice towards homosexual people and equal marriage, since although this position does not directly infer the creation of laws that promote or stop the regulation of these legal figures, it should not be overlooked that the people who come from political parties and who make up the Federal and State Congresses are the that through ideological positions and sometimes campaign promises, they are the ones who have the power to influence the approval of these laws. By studying the position taken by the population, it was possible to determine what are the main arguments against equal marriage? And what public policies can be carried out to generate a progressive advance in the opinion of the citizens, which allows

1 Juez de Primera Instancia del Sistema Penal Acusatorio del Tribunal Superior de Justicia del Estado de Chihuahua. Maestro en Derechos Humanos y Perspectiva de Género por el Instituto Estatal de Seguridad Pública de Ciudad Juárez, México. Correo electrónico: dirismsome@hotmail.com; ORCID: 0000-0001-6482-1770. 
selecting candidates with prohumanist foundations? To clarify the above, an evolutionary analysis of marriage was carried out at a national and international level, taking up studies by Cabrera Priego, Calvo Caravaca, Salina Hernández among others, later a quantitative, non-experimental, cross-sectional and descriptive investigation was carried out, with a non-experimental sample, probabilistic for convenience of 150 people, to whom a questionnaire with 36 items was applied.

Keywords: equal marriage, dissident groups, prejudice, homosexuals

\section{Introducción}

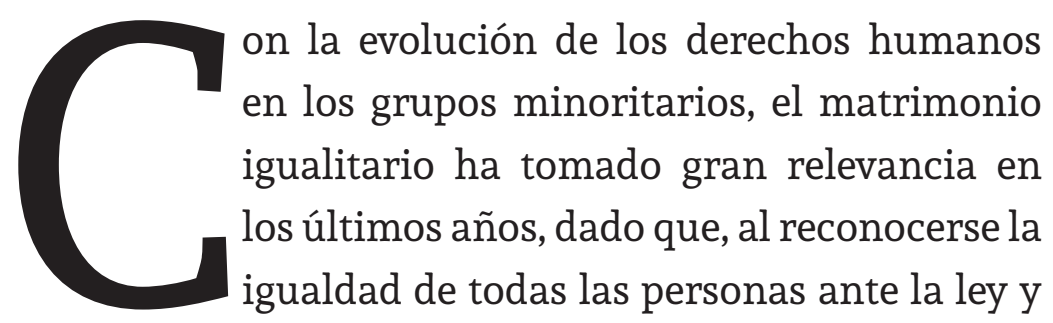
la prohibición de la discriminación, a lo largo del mundo se han realizado diversas modificaciones en las leyes de países en Europa y en América Latina, entre ellos algunos estados de la república mexicana. Pese a lo anterior, en otros estados del país y en la federación, múltiples propuestas de reforma o leyes han sido frenadas por las posturas que miembros del Congreso tienen respecto al matrimonio igualitario.

En relación con lo anterior, no debe pasarse por alto que los miembros del Congreso son elegidos mediante la votación de los ciudadanos mexicanos, por una parte, los diputados federales son seleccionados cada tres años, mientras que los senadores federales son selectos cada seis años. Para alcanzar su objetivo, previamente se tiene que hacer un trabajo de selección interna en cada partido político que cumple con los requisitos para nombrar a un representante, quien posteriormente realiza una labor de campaña para acumular votos en su favor y todo este trabajo para seleccionar a los representantes de la ciudadanía gira en torno a las agendas políticas 
que cada candidato tiene, basándose en propuestas y promesas de campaña que resultan atractivas para los gobernados y que se realizan con la intención de que el país progrese.

$\mathrm{Al}$ establecerse el proceso democrático en el país, resulta de relevancia establecer la postura de la población hacia el matrimonio igualitario, dado que entre mayor aceptación tenga en los miembros de una comunidad, mayor será la relevancia y promoción que le darán los partidos políticos en sus propuestas de campaña, dando una mayor posibilidad de que los representantes políticos progresistas se encuentren en condiciones idóneas para aprobar leyes de carácter igualitario que estén en concordancia con la normativa internacional y nacional ya existente.

El presente trabajo realizará una recopilación histórica de los diversos momentos que han permitido la evolución de los derechos humanos y de cómo las luchas de los grupos minoritarios han logrado un avance progresivo en la creación de leyes que les den el reconocimiento que tienen de sus derechos inalienables; para posteriormente enfatizar cuáles son las posturas que la sociedad tiene al respecto y qué ideologías o grupos pueden influenciar en el avance o retroceso de creación de normas, para que con este trabajo, una vez que se tengan identificadas las opiniones en contrario, se puedan crear políticas públicas para tener una mejor aceptación respecto al matrimonio igualitario.

Como fundamento es indispensable referir que a lo largo de la historia y la evolución de la humanidad se ha llevado a cabo una lucha constante por el disfrute de aquellos derechos que les corresponden tanto a hombres y mujeres por el simple hecho de ser parte de la especie humana, atributos inalienables que hoy en día denominamos "derechos humanos", los cuales por sus características particulares no son otorgados por los estados, sino que, por el contrario, se genera la obligación del reconocimiento y protección de los mismos mediante reglamentos, leyes, tratados internacionales y resoluciones que son de carácter obligatorio. La declaración gradual de estos derechos en la historia cultural del ser humano se ha generado de manera exponencial y masiva en periodos de gran transformación social y mediante cambios radicales de paradigmas, tal y como aconteció en 1789 con la "Declaración Universal de los Derechos del Hombre", adoptada por la Asamblea General de las Naciones Unidas y renombrada en 1952 para quedar como la "Declaración Universal de Derechos Humanos” (Tunnermann, 1997).

En este nuevo ambiente de cambio internacional, generado durante décadas por factores políticos, consecuencia de la segunda posguerra y el surgimiento de la Organización de las Naciones Unidas (ONU), 
se intensificaron diversos movimientos que alcanzaron un mayor clamor social a mediados de los años sesenta, como aquellos que pugnaban por la igualdad entre personas blancas y de color, la demanda de las mujeres por ser reconocidas y tratadas en igualdad ante los hombres, así como la identificación y protección de grupos vulnerables; momento que fue aprovechado por personas con una identidad sexual diversa a los heterosexuales para elevar sus pretensiones, oponiéndose a la violencia y segregación que habían sufrido hasta ese momento, estructurando así un colectivo conformado por lesbianas, gays, bisexuales y transexuales (LGBT), quienes en ese frente común se oponían a la opresión e invisibilización de la cual habían sido víctimas (Serrato Guzmán y López Sánchez, 2018).

Una vez estructurado el colectivo LGBT, se incorporaron diversos grupos segregados por su identidad y expresión de género, o por su condición biológica, a decir personas transexuales, transgénero, travesti e intersexuales (LGBTTTI), quienes en un primer momento, de manera conjunta, generaron un avance en la conciencia social y política de varios países a lo largo del mundo, entre ellos México, teniendo un retroceso a finales de los años ochenta por el surgimiento de enfermedades relacionadas directamente con la homosexualidad (Martínez Aguayo, 2009). Pese al panorama desfavorable, el movi- miento se incrementó con un discurso de igualdad y respeto, generando que diversos países adecuaran su normativa interna para emparejarse a los instrumentos internacionales, modificando diversas figuras legal y socialmente aceptadas, pero que por sus propias definiciones o requisitos se encontraban tildadas de prejuicios, entre las cuales se puede encontrar el matrimonio (Cabrera Priego, 2016).

$\mathrm{Al}$ respecto de estos derechos, el matrimonio de personas del mismo sexo comenzó a legalizarse a principios del año 2001, siendo México en fecha del 4 de marzo del año 2010 la decimocuarta nación del mundo en agregarlo a su legislación, recorrido que inició con el proyecto para reformar la Ley de Sociedad de Convivencia para el Distrito Federal de fecha del 24 de noviembre del año 2009 (Bustillos, 2011). Como consecuencia inmediata, la Asamblea Legislativa del Distrito Federal modificó el Código Civil, ampliando el matrimonio para personas homosexuales, la cual a su vez fue sometida a una revisión por parte de la Suprema Corte de Justicia de la Nación (SCJN), máximo órgano jurídico del país, el cual resolvió en la Acción de Inconstitucionalidad 2/2010 lo siguiente:

El Tribunal en Pleno determinó por mayoría de 9 votos, reconocer la validez de la reforma verificada al artículo 146 del Código Civil para el Distrito Federal, que define al matrimonio como la unión 
libre de dos personas para realizar la comunidad de vida, en donde ambos se procuran respeto, igualdad y ayuda mutua. En ese sentido, se estimó que es competencia del legislador ordinario, consagrada en la propia Constitución Federal, regular lo relativo a la materia civil, dentro de la cual se comprende la institución del matrimonio, sin que la Norma Fundamental lo defina ni limite la función legislativa en ese sentido. Se sostuvo que el concepto de matrimonio ha evolucionado y superado su concepción tradicional, y que, en la actualidad, se reconoce que, en el mismo, no cuenta únicamente como elemento importante el de la función reproductiva. (Suprema Corte de Justicia de la Nación, 2010)

Luego, se agregaron a la lista diversos estados que reconocieron el derecho de las personas del mismo sexo a unirse mediante el matrimonio civil, tales como Baja California, Campeche, Chiapas, Puebla, Quintana Roo, Jalisco, Colima, Morelos. Hasta hoy, cada entidad federativa posee un Código Civil en el que se establecen y registran los principales requisitos para la institución del matrimonio, siendo que en la mayoría de los 32 estados que conforman la república mexicana, la definición de matrimonio no es lo suficientemente específica para incluir parejas homosexuales. Si bien es cierto, en varios de ellos existen uniones solemnes o figuras equipara- das, estas no son reconocidas a tal grado como lo sería el matrimonio, pese a que la SCJN dio apertura desde el año 2010 a la posibilidad de adecuar las legislaciones locales para que se encontraran en armonía con la Constitución Política de los Estados Unidos Mexicanos (CPEUM) y los tratados internacionales de los que México es parte (Sánchez, 2017).

Paradójicamente, mientras que en el ámbito legal los derechos de las personas homosexuales han avanzado día a día, reconociendo y amparando los matrimonios entre personas del mismo sexo, en otros sectores a nivel mundial se han puesto barreras por ideas contrarias, tal es el caso de la Iglesia en sus diversas acepciones y grupos dedicados a la fe, al referir que dichas uniones impiden generar la procreación, aunado a que en los territorios que se ha aprobado es un claro desafío a la libertad de creencia y al correcto desarrollo de la familia, como tercer punto genera una grave afectación psicológica, física, espiritual y atenta contra los motivos de las creencias religiosas. No pasa desapercibido, que también centran sus argumentos en que las leyes van en contra de la palabra de Dios, tal y como lo establecen los libros religiosos, lo que a su vez lleva a las personas relacionadas a perder la gracia del señor (López, 2017).

Como se refirió anteriormente, entre los derechos por los cuales el colectivo LGBTTTI ha luchado se encuentra el matrimo- 
nio y no debe perderse de vista que, si bien es cierto, en muchos tratados internacionales el matrimonio se plasma o se infiere como la unión entre un hombre y una mujer, quienes tienen la finalidad de formar una familia; la cual deja de lado la unión entre parejas del mismo sexo, puesto que en pocos, o en ningún documento de principios del siglo pasado, se especifica que la diferencia de sexo entre los contrayentes sea un punto a resaltar en el matrimonio, ya que la unión de dos hombres o dos mujeres era algo impensable en ese momento al ser una situación vedada o invisibilizada y que, por ende, al no tratarse de un tema de disputa social, no era necesario que el derecho se encargara de proteger y reconocer dichas uniones (Calvo Caravaca y Carrascosa González, 2009).

Con tal argumento y con una política proteccionista de la definición clásica de familia (padre, madre e hijos), se generó un retroceso alarmante en derechos igualitarios. En el panorama nacional, las marchas y protestas contra el reconocimiento de derechos igualitarios se intensificaron en el año 2016 y causaron que los grupos opositores se hicieran más visibles, estableciendo que estos movimientos mayormente han sido impulsados por la Iglesia católica, así como la Iglesia evangelista, creando un frente común contra países latinos que impulsaron cambios en sus normas para ampliar los derechos de la comunidad homosexual, tomando como consigna la protección de la vida y la familia. Situación que se acrecentó en el mandato del presidente Enrique Peña Nieto, dado que impulsó un paquete de reformas ante el Congreso de la Unión para que fuera posible encontrar una concordancia entre los ordenamientos legales del país y los criterios tomados por la SCJN, bajo el entendido que diversos artículos de los Código Estatales restringían los derechos de las personas homosexuales que quisieran contraer matrimonio; siendo necesario descartar los prejuicios y malas apreciaciones sobre el matrimonio, por ejemplo, que este solo puede ser celebrado entre un hombre y una mujer, con la finalidad de preservar a la familia mediante la procreación; con lo cual se trataba de evitar de esa manera la necesidad de resolver asuntos estado por estado mediante amparos ante el máximo tribunal del país, reiterando que el referido paquete, encontrando una reacción inmediata del Frente Nacional de la Familia (FNF) con apoyo de la Iglesia católica, quien llamó a votar en contra del Partido Revolucionario Institucional y de aquellos que promovían y apoyaban la ideología de género, teniendo como consecuencia que la reforma de ley presentada se archivara (López, 2017).

Ante la situación que vive la sociedad mexicana, con avances y retrocesos sobre la creación y aplicación de leyes de índole igualitario, el matrimonio es uno de los temas más polémicos en los últimos años, 
principalmente al enfrentarse a legislaciones estatales que impiden la celebración de este acto jurídico, así como pensamientos disidentes de personajes individuales y colectivos de la sociedad que en su conjunto impiden la modificación de las normas que garantizan una ampliación en la protección de los derechos humanos del colectivo LGBTTTI. Al respecto, es relevante identificar los propulsores que intervienen para hacer viable la creación de normas que permitan una mayor protección a las personas y que estén en armonía con las resoluciones de la SCJN, de lo contrario no sería posible exponer las mecánicas y el curso de acción a seguir de manera clara, para superar las opiniones en contra del matrimonio igualitario. Puesto que, como ya se refirió, si no existe una concordancia entre las legislaciones estatales y federales del país que amparen y protejan este tipo de derechos, no se podrá realizar un cambio de paradigma social (Calvo Caravaca y Carrascosa González, 2009).

Partiendo de los temas tratados, surgió la necesidad del presente trabajo cuyo objetivo versó en analizar la percepción de la sociedad en Ciudad Juárez, Chihuahua, con respecto al prejuicio hacia personas homosexuales y su derecho al matrimonio igualitario, puntualizando si las oposiciones generadas al respecto se basaban en argumentos retrogradas tildados con prejuicios sociales y culturales.

\section{Acepción del matrimonio a lo largo de la historia}

El matrimonio ha evolucionado junto con la historia de la humanidad, por lo que se ha definido de diversas maneras desde la creación del derecho romano y una acepción conyugal de este es la unión entre dos personas del sexo opuesto, hombre y mujer, quienes se unen en deberes y obligaciones constantes y que deben velar por ampararse y apoyarse mutuamente, cuyo objetivo es la procreación, crianza y educación de hijos. Los cónyuges sellan y renuevan su unión por medio de actos conyugales, actos encaminados a completar la procreación mediante la unión sexual y así generar vida, para posteriormente guiarla y educarla. La figura del matrimonio es importante por su propia estructura, reiterando que la generación y crianza de los hijos es el punto más alto e importante de dicha unión y, para lograr esto y generar un entorno idóneo para los hijos, se debe de velar y perpetuar preceptos tales como la fidelidad y la monogamia entre los contrayentes, con lo que se colocan las bases para la convivencia entre los cónyuges y, a su vez, generar un entorno idóneo donde se trasmitan dichos valores a una nueva generación (Finnis, 1994).

Es importante destacar que se puede realizar una descripción desde una nueva visión, más inclusiva al describirlo como: 
La unión de dos personas (sean éstas de igual o distinto sexo), quienes se comprometen a amarse románticamente y a cuidarse mutuamente, compartiendo las cargas y beneficios de la vida doméstica. Es, esencialmente, una unión de corazones y mentes, elevada por cualquier forma de intimidad sexual que ambas partes consideren como deseable. El Estado debiese reconocer y regular el matrimonio porque tiene un interés en la existencia de uniones estables y románticas y en las necesidades concretas de los cónyuges y de los niños que ellos puedan decidir criar. (Girgis, George y Anderson, 2020, p. 90)

Las definiciones previamente reseñadas dejan en claro que el matrimonio no es un concepto inmutable, sino que, por el contrario, evoluciona, aunque de una manera pausada y gradual para cubrir las necesidades existentes en ese momento respecto a los valores, estándares culturales y cánones sociales que a su vez también se manejan de una manera progresiva.

Respecto a los países europeos, los tratados internacionales, tales como la Carta de los Derechos Fundamentales de la Unión Europea, encaminan la creación de una nueva definición de matrimonio, esto mediante una aclaración que hace el Tribunal Europeo de Derechos Humanos (TEDH), puesto que, si bien es cierto que en las sentencias resueltas por dicho tri- bunal se establece que no se puede obligar a los estados miembros a que generen políticas para reconocer el matrimonio igualitario, al determinar que dicha figura tiene una acepción que varía de miembro a miembro, sí establece que el artículo 9, al definir la figura en comento, no ingresa calidades como hombres y mujeres para limitar la unión solo entre personas de sexo opuesto, con dicha manifestación se resalta que los países europeos toman un punto medio o neutral respecto a las definiciones de los géneros, máxime que el Parlamento Europeo en su resolución del 8 de febrero de 1994 emitió diversas recomendaciones para que los países miembros tomen acciones encaminadas a generar una igualdad de acceso a las personas homosexuales, en vías de poner fin a las prohibiciones que impiden el acceso al matrimonio igualitario o a regímenes jurídicos similares. También emitió recomendaciones para que aquellos Estados que sí permiten dichas uniones las impulsen y cuiden, cuando existe tránsito entre estos países (Soriano Martínez, 2011).

Estas posturas han evolucionado a la par de los movimientos igualitarios, es así que el TEDH determina que las leyes que solo contemplan y permiten las uniones civiles de personas heterosexuales y no de personas con otra orientación, o aquellas legislaciones que impidan a las parejas del mismo sexo acceder a las uniones civiles, son violatorias de los artículos 14 y 
8 del Convenio Europeo, tal y como pasó en los casos Vallianatos y Otros vs. Grecia de 2013 y Oliari y Otros vs. Italia en el 2015 respectivamente. No solo en Europa se han dado estos cambios, en el sistema interamericano se han generado instrumentos que tienen como principal objetivo ser una guía orientadora de los derechos básicos que deben ser respetados por cada estado miembro y que permitan aseverar que existe un estado de derecho, donde el gobierno tiene una doble obligación legal, por una parte, no generar violación alguna a los derechos de los gobernados y, por otro lado, generar los medios y vías necesarias para garantizar la protección de estos derecho; tal como lo es la Convención Interamericana contra Toda Forma de Discriminación e Intolerancia, donde se retoman temas como la protección de la identidad y la expresión de género.

Es así como la Corte Interamericana de Derechos Humanos (Corte IDH), en su opinión consultiva OC-24/17, de fecha 24 de noviembre de 2017, al dar respuesta a la solicitud realizada por Costa Rica, informa que la Convención Interamericana de Derechos Humanos (CIDH) señala la protección para la familia, pero no limita esta definición al término conservador, puesto que teleológicamente esta debe abarcar todas aquellas estructuras formadas por personas que tienen un interés afectivo y generan estructuras de relaciones estables. De igual manera, si estas estructuras están conformadas por parejas del mismo sexo, el Estado puede tomar la opción más viable y eficaz, para garantizar los derechos humanos de dichas personas ampliando las figuras jurídicas ya existentes, sin necesidad de crear figuras nuevas que respalden los mismos derechos bajo un nombre diverso, puesto que sí el Estado parte opta por esta opción, se corre el riesgo de perpetuar una acción discriminatoria (Corte IDH, 2017).

Con lo antes referido, se establece de manera clara que el matrimonio igualitario es la unión entre dos personas, de las cuales no importa el sexo o género de los contrayentes, dado que, llevado al ámbito civil, debe establecerse que es la unión de voluntades, con la finalidad de llevar una vida en común y democráticamente decidida, encaminada a erradicar la discriminación hacia el colectivo LGBTTTIQ, para que no se vea en la necesidad de ser marginado en la sociedad y en los puntos de reunión de la misma, generando un modelo de inclusión social, familiar y generacional en México (Salinas Hernández, 2017).

Pese a que este concepto no es retomado por la SCJN en ninguna de sus resoluciones, es un término que respeta el principio de no discriminación, puesto que el mismo permite que todas las parejas que se puedan conformar en un determinado lugar y momento, se ven en las mismas condiciones para acceder a dicha figura; por otro lado, denominarlo matrimonio 
gay o matrimonio para las personas LGBTTTIQ resultaría en una clara discriminación, dado que no se puede reconocer un derecho segregando y etiquetando de esta manera a las personas a las que se debería de amparar, desvirtuando esa igualdad de acceso que se busca para todas las personas (Quintana Osuna, 2017).

\section{Matrimonio igualitario en México}

En México, las sociedades de convivencia fueron las primeras muestras de progreso para las uniones de personas de este o distinto sexo, en las que se generaron deberes y se confirieron derechos, de los cuales se desprende de alguna manera entre los contrayentes lazos de parentesco, las cuales fueron aprobadas en el 2006 en la Ciudad de México (anteriormente conocida como Distrito Federal). Con diverso nombre en el estado de Coahuila, se legislaron las uniones registradas bajo el Pacto Civil de Solidaridad, las que solo se limitan a tres derechos como lo son los alimentos, las sucesiones y la tutela. Por otro lado, en la figura de matrimonio establecida en la legislación mexicana, se dan mayores prerrogativas como la nacionalización y acceso a la salud en favor de uno de los cónyuges (González Pérez, 2007).

En el 2009, el anterior Distrito Federal autorizó el matrimonio igualitario, generando el surgimiento de varios actores con puntos de vista contrarios entre sí; por una parte, a las personas que desean el reconocimiento de estos derechos inherentes y, por otro lado, los actores sociales e institucionales, con el ánimo de frenar el avance de los derechos de las personas del mismo sexo al alterar las normas que hasta ese momento estaban pensadas para los heterosexuales, lo que generó una gran sensación de pánico, moral y social, en los grupos conservadores de la capital mexicana, quienes por miedo y con un panorama de inconformidad colectiva, respondieron de manera poco positiva a las ideas del matrimonio para personas del mismo sexo, así como a la adopción y a la homoparentalidad.

Para Toro-Alfonso (2012), en el pensamiento de los grupos disgregantes colocan a los integrantes del colectivo, a las interacciones que tienen en torno a la sociedad y a la manera en cómo se comportan en un mismo punto y en un extremo dicotómico de persona a los heterosexuales, siendo que a los primeros de ellos los definieron como personas contaminadas, anormales y desviadas, y a los heterosexuales como el estereotipo perfecto de estándar social al ser personas puras, normales y naturales, ensalzando los valores de aquellos que tienen preferencia por seres humanos del sexo opuesto. Con esta forma de pensar, los grupos disgregantes llegan a la conclusión de que las personas que no son como ellos generan una amenaza, capaces de cometer atrocidades sexuales y, como eje rector que son, capaces de cometer viola- 
ciones en perjuicio de los menores de edad que pudieran estar a su cargo, capaces de contagiar, como si de una enfermedad se hablara, la homosexualidad y el lesbianismo a los niños, niñas y adolescentes que en determinado caso estén a su cuidado (Toro-Alfonso, 2012).

\section{Posturas en contra del matrimonio igua- litario}

Con un tema tan controversial la sociedad se divide en cuatro posturas, por una parte, las personas que abiertamente reconocen los derechos de la comunidad LGBTTTI; las que consideran que sí es correcto el matrimonio igualitario, pero no la adopción homoparental; las que consideran que no debe denominarse matrimonio a la unión de personas del mismo sexo pese a estar de acuerdo con la unión y sus consecuencias; finalmente las que se oponen totalmente al matrimonio igualitario y al reconocimiento de todos los derechos que esto conlleva para las personas homosexuales. Estas posturas por lo regular se pueden separar en tres áreas diversas, por una parte, las que provienen de los grupos religiosos, las que tienen su origen de los actores políticos y, finalmente, puede establecerse como una tercera vertiente la que proviene de los ciudadanos, pese a que dichas oposiciones generalmente se encuentran sustentadas en las dos anteriores (Salinas Hernández, 2017).
El primer grupo en análisis serán los grupos religiosos católicos, de los cuales tienen una problemática externa, puesto que la evolución de los derechos humanos ha generado que el Estado modifique diversas legislaciones que regulan las relaciones de los gobernados mediante la secularización de figuras que social y culturalmente, que si bien no tienen su origen en las instituciones religiosas, sí proceden del orden natural del ser humano, donde establecen los grupos religiosos que solo las relación sexuales entre seres humanos de diverso sexo permiten la concepción de la vida y por otro lado, el predicamento interno que surge como respuesta directa a la aprobación de las leyes de índole igualitaria, al ponerse en entredicho si el Estado obliga a los grupos religiosos a que modifiquen las normar internas que tienen y acepten para referirse al matrimonio y pueden continuar con sus reglamentos. A saber, en Europa el Pontificio Consejo para la Familia de la Iglesia católica se pronunció al respecto de la resolución del Parlamento Europeo del día 16 de marzo del 2000, sobre la equiparación de la familia y las uniones de hechos; al señalar que esta resolución es una agresión en contra del matrimonio establecido entre un hombre y una mujer, al ser el núcleo natural y antropológicamente aceptado, del que se desarrolla toda sociedad, puesto que solo esta relación fundada en el amor puede dar origen a la vida (Arlettaz, 2015). 
$\mathrm{Al}$ respecto, la finalidad de dar origen a una nueva vida no es el más importante de los objetivos del matrimonio, pero sí es de alta relevancia, dado que al realizar el coito, independientemente de que se consume el amor existente entre las parejas que son sexualmente complementarias, esta acción se encamina a la generación y crianza de niños, lo que forja a la pareja y la consolida de tal manera que la educación del fruto de esta relación se trasmitirá de generación en generación, situación que no puede acontecer con una unión entre dos personas del mismo sexo, puesto que genitalmente no se complementan (Girgis, George y Anderson, 2020).

De igual manera, no hay que pasar por alto que las instituciones religiosas contemplan el matrimonio como un sacramento, por medio del cual Dios expresa su amor hacia las parejas que se unen mediante dicho vínculo, así como a la especie humana; mediante esta muestra de amor, Dios desea que se unan para generar nuevas vidas denominadas hijos, a las cuales se van a entregar, demostrando de esta manera ser discípulos diligentes de Jesús (Flores, 1995).

Esta serie de argumentos ha sido tomada desde los más altos niveles de las organizaciones religiosas, un ejemplo de esto, en la Iglesia católica, fue el realizado por el papa Francisco, quien en el año 2016 refirió estar de acuerdo con las personas que protegen a la familia y a la vida, esta- bleciendo que apoya a los obispos que se han sumado a la sociedad para establecer su inconformidad de que se acepten los matrimonios igualitarios, aunado a que es necesario guiar a las personas en los ámbitos de la fe (Excelsior, 2016) y, a su vez, la Arquidiócesis de México tomó mayor impulso, inclusive se realizaron diversas manifestaciones en el semanario católico Desde la fe por los representantes en México de la Iglesia católica. En la publicación se establece que la relación sexual es una expresión de amor que se genera entre un hombre y una mujer, a los que se les denomina cónyuges y los cuales están unidos en matrimonio; inclusive se establece que las personas homosexuales como cualquier ser humano tienen desviaciones, por lo que tienen que velarse en invitar a los mismos para que se acerquen a Dios, pero esto no quiere decir que las relaciones homosexuales sean aceptadas. De igual manera, señalan que el único matrimonio que es aceptado por la Iglesia es el celebrado entre un hombre y una mujer, cuya finalidad de procrear hijos, tal y como se establece en las escrituras y así como lo enseñó Dios, aceptar lo contrario sería permitir que el humano perdiera el camino y se dejara llevar solamente por el deseo carnal, dejando todos los demás dones que tiene, máxime que las relaciones sexuales entre personas del mismo sexo es un pecado grave (Rivera, 2016). 
Aunado a lo anterior, los miembros religiosos condenaron a los ministros de la SCJN puesto que establecieron que los mismos han superado sus límites e interferido en la ley natural, por lo que, aunque puedan modificar las leyes terrenales, no podrán escapar de los tribunales de Dios. De igual manera, motivaron a sus feligreses a poner atención en las propuestas de los partidos políticos y a sus candidatos en las elecciones, dado que no deben estar en contra de los valores que la Iglesia promulga ni en contra de la familia, la vida, la maternidad y la familia tradicional; es obligación de los que están bautizados ejercer en un voto consiente para frenar los ataques a los valores de la fe, por la sociedad política del país (La Jornada, 2010).

Es así que cabecillas de las congregaciones religiosas impulsaron que sus miembros castigaran a los partidos políticos que tuvieran una ideología de género, evitando votar por ellos, puesto que atacan los derechos naturales que promulga la religión. Esta presión en los grupos políticos fue muy notoria, ya que inclusive en el partido Movimiento de Regeneración Nacional (MORENA), representada por el candidato a la presidencia Andrés Manuel López Obrador, estableció que los temas importantes para su partido son la honestidad y el combate a la corrupción, y no así el matrimonio y la adopción realizadas por personas del mismo sexo (Animal Político, 2015).
Esta coerción realizada desde la Iglesia permea a tal nivel que inclusive se ha establecido que miembros de asociaciones religiosas intervienen de manera interna en partidos políticos, tal y como se señaló en el Partido Encuentro Social (PES) fundado por el doctor en Derecho Hugo Erick Flores, partido al cual se le acusó de estar conformado por miembros de diversos cultos, de los cuales inscribieron a siete de ellos como delegados o presidentes de asambleas, lo que género que se abrieran dos procedimientos oficios para investigar la situación (Animal Politico, 2014).

Mediante la unión de los argumentos de estos dos grupos políticos y religiosos es como se comparten al resto de la sociedad, los cuales toman como suyos dichos argumentos, a la par de que se forman grupos religiosos y de la sociedad civil como por ejemplo el Frente Nacional de la Familia (FNF), Consejo Mexicano de la Familia (ConFamilia), Unión Nacional Cristiana por la Familia, Gladium MX, Conferencia Nacional de Liderazgo Cristiano, Coalición de Grupos a Favor de la Vida y la Familia, Comisión Ciudadana de Principios Éticos, los cuales se oponen fervientemente a iniciativas que atentan contra la vida tal y como lo es la legalización del aborto o aquellas que van en contra de la familia tradicional, como lo es la aprobación del matrimonio igualitario (Notipress, 2020).

La estructura que permite influenciar o dar a conocer el tema de los matrimonios 
igualitarios no se realiza en forma escalonada, partiendo de los puntos más altos de la estructura social, por el contrario, son una serie de factores organizados de manera piramidal que parte de las bases generadoras del poder. Es decir, en un estado de derecho cimentado en la base de la democracia, surge de manera relevante la opinión social que se tiene respecto a un tema en específico, puesto que dependiendo del nivel de aceptación o rechazo de la sociedad, surgen los puntos de interés de los partidos políticos que existen en el país y los cuales, dependiendo del perfil que tienen, retoman los temas de interés de la sociedad para poder elevar la cantidad de personas que votarán por ellos, con el fin de lograr los puestos políticos que desean tener.

Es de esta manera como la percepción de la sociedad es relevante para la creación de leyes, puesto que las plataformas políticas manejadas, como ya se puntualizó, dependen de las necesidades de la sociedad y de aquellos elementos que les den una mejor postura; cuando se consiguen los diferentes puestos políticos se va escalonando en el poder del Estado mexicano hasta que se logra llegar en la división tripartita del Estado en el poder legislativo, siendo el recinto estatal o federal donde se crean las normas que rigen a la sociedad y si la postura del partido es una forma tradicional que se inclina por la existencia de la familia tradicional y creencias de orden religioso, las votaciones para la aproba- ción de una ley en favor del matrimonio igualitario serán menores o se encontrará un mayor nivel de oposición que frene dichas leyes.

Teniendo a la vista que el reconocimiento de los derechos humanos no es una cuestión de opinión pública que corresponda a las masas decidirlo y que, claramente, no debe de estar sujeto a la vox populi, sí son las personas las que colocan a los políticos en el poder y por tal situación es relevante saber la postura de la población para poder abordar de manera clara y precisa las oposiciones que existen, mediante políticas públicas que concienticen en la universalidad, progresividad y alcance de los derechos humanos.

\section{Metodología}

Este trabajo de investigación fue de diseño cuantitativo, no experimental, ya que no se manipula ninguna de las variables; transversal, ya que los datos se recolectaron en un solo momento (Hernández Sampieri, Fernández Collado y Baptista Lucio, 2010). Se realizó una investigación de tipo descriptivo para conocer los prejuicios de la sociedad con respecto a las personas homosexuales y matrimonio igualitario. Se utilizó una muestra no probabilística por conveniencia de 150 participantes, se consideró como sujetos de estudio a ciudadanos mayores de 15 años, entre ellos perso- 
nas religiosas, profamilia ${ }^{2}$, miembros del colectivo LGBTTTIQ y personas heterosexuales, mismos que se localizaron en zonas con mayor tránsito, entre ellas la zona centro, 16 de Septiembre, Plutarco Elías Calles, Adolfo López Mateos y San Lorenzo. Los datos fueron recabados a través de un cuestionario, el cual fue aplicado directamente a cada uno de los participantes.

Respecto a la operacionalización de las variables, se procedió a revisar las escalas existentes en la literatura, es así que prejuicio hacia los homosexuales, se valoró a partir de instrumentos propuestos por (Rodríguez Castro, Lameiras-Fernández, Carrera Fernández y Vallejo Medina, 2013; Moral de la Rubia y Martínez Sulvarán, 2011), para matrimonio igualitario, se adaptaron las escalas de (Ordóñez, Díaz Velez y Soto Cáceres, 2019; Grigoropoulos y Panos, 2016; Moral de la Rubia y Valle de la O, 2011). Los constructos fueron valorados a través de una escala tipo Likert con 5 puntos de asignación de respuesta, que van desde "Totalmente en desacuerdo" hasta "Totalmente de acuerdo". En la Tabla 1 se presenta la escala utilizada para medir cada una de las variables. En el instrumento se incluyeron 36 ítems: prejuicio hacia los homosexuales, 19; matrimonio igualitario, 17. Los datos recabados fueron

2 Movimiento social conformado por personas e instituciones, de corte conservador que tienen por consigna promover y defender los tres pilares de la sociedad; siendo estos la vida, la familia y las libertades. analizados a través de la herramienta estadística Statistical Package for the Social Sciences (SPSS) versión 22.

Tabla 1. Operacionalización de variables

\begin{tabular}{|c|c|}
\hline $\begin{array}{l}\text { Prejuicio hacia los } \\
\text { homosexuales }\end{array}$ & Matrimonio igualitario \\
\hline $\begin{array}{l}\text { Acostumbro a asistir } \\
\text { de manera frecuente } \\
\text { a algún culto, adora- } \\
\text { ción, misa, etc. }\end{array}$ & $\begin{array}{l}\text { El matrimonio no debe ser } \\
\text { exclusivo para los hetero- } \\
\text { sexuales. }\end{array}$ \\
\hline $\begin{array}{l}\text { En mi familia cerca- } \\
\text { na hay homosexua- } \\
\text { les. }\end{array}$ & $\begin{array}{l}\text { El matrimonio entre perso- } \\
\text { nas del mismo sexo socava } \\
\text { el significado de la familia } \\
\text { tradicional. }\end{array}$ \\
\hline $\begin{array}{l}\text { En mi familia amplia } \\
\text { hay homosexuales } \\
\text { (tíos, tías, primos, } \\
\text { primas). }\end{array}$ & $\begin{array}{l}\text { Dos padres amorosos del } \\
\text { mismo sexo pueden propor- } \\
\text { cionar la misma calidad de } \\
\text { crianza y orientación como } \\
\text { hombre y mujer. }\end{array}$ \\
\hline $\begin{array}{l}\text { En mi grupo de } \\
\text { amigos, laboral o } \\
\text { académico, hay ho- } \\
\text { mosexuales. }\end{array}$ & $\begin{array}{l}\text { Un propósito principal del } \\
\text { matrimonio es proporcionar } \\
\text { estabilidad en una relación } \\
\text { amorosa. Las parejas del mis- } \\
\text { mo sexo deben tener este de- } \\
\text { recho legal a su disposición. }\end{array}$ \\
\hline $\begin{array}{l}\text { Asistiría a una fiesta } \\
\text { si supiera que va a ir } \\
\text { un homosexual. }\end{array}$ & $\begin{array}{l}\text { El reconocimiento del ma- } \\
\text { trimonio entre personas del } \\
\text { mismo sexo representa una } \\
\text { amenaza para la sociedad } \\
\text { porque las escuelas se verán } \\
\text { obligadas a enseñar que la } \\
\text { homosexualidad es normal. }\end{array}$ \\
\hline $\begin{array}{l}\text { Trabajaría con un } \\
\text { homosexual. }\end{array}$ & $\begin{array}{l}\text { La protección matrimonial, } \\
\text { como la seguridad social y los } \\
\text { beneficios de atención médi- } \\
\text { ca, debe estar disponible para } \\
\text { parejas del mismo sexo. }\end{array}$ \\
\hline $\begin{array}{l}\text { No me molesta la } \\
\text { idea de tener amigos } \\
\text { homosexuales. }\end{array}$ & $\begin{array}{l}\text { El matrimonio entre perso- } \\
\text { nas del mismo sexo fortalece- } \\
\text { rá la moral de la sociedad al } \\
\text { apoyar la igualdad. }\end{array}$ \\
\hline $\begin{array}{l}\text { Los homosexuales } \\
\text { que viven en pareja } \\
\text { deberían tener el } \\
\text { derecho de adoptar } \\
\text { niños. }\end{array}$ & $\begin{array}{c}\text { Apoyo a personas que no son } \\
\text { heterosexuales que buscan } \\
\text { derechos de matrimonio. }\end{array}$ \\
\hline
\end{tabular}

Continúa... 


\begin{tabular}{|c|c|}
\hline $\begin{array}{l}\text { Prejuicio hacia los } \\
\text { homosexuales }\end{array}$ & Matrimonio igualitario \\
\hline $\begin{array}{l}\text { Los homosexuales } \\
\text { son capaces de tener } \\
\text { vínculos amorosos } \\
\text { tan estables y durade- } \\
\text { ros como las parejas } \\
\text { heterosexuales. }\end{array}$ & $\begin{array}{l}\text { Debido a que más personas } \\
\text { tendrán los beneficios del } \\
\text { matrimonio, la familia será } \\
\text { fortalecida por el reconoci- } \\
\text { miento de los matrimonios } \\
\text { del mismo sexo. }\end{array}$ \\
\hline $\begin{array}{l}\text { Las personas homo- } \\
\text { sexuales tienen los } \\
\text { mismos derechos que } \\
\text { las personas hetero- } \\
\text { sexuales. }\end{array}$ & $\begin{array}{l}\text { Hombres y mujeres se com- } \\
\text { plementan naturalmente, } \\
\text { por lo tanto, una unión entre } \\
\text { dos hombres o dos mujeres } \\
\text { no debe ser reconocida en el } \\
\text { matrimonio. }\end{array}$ \\
\hline $\begin{array}{l}\text { Me incomoda si dos } \\
\text { hombres se toman de } \\
\text { la mano. }\end{array}$ & $\begin{array}{l}\text { La legalización del matrimonio } \\
\text { de personas del mismo sexo es } \\
\text { un paso importante hacia la } \\
\text { aceptación de personas que no } \\
\text { son heterosexuales. }\end{array}$ \\
\hline $\begin{array}{l}\text { Pienso que se debe } \\
\text { respetar al colectivo } \\
\text { homosexual. }\end{array}$ & $\begin{array}{l}\text { Un propósito principal del } \\
\text { matrimonio es criar hijos, } \\
\text { por lo tanto, solo un hombre } \\
\text { y una mujer debería estar } \\
\text { casados }\end{array}$ \\
\hline $\begin{array}{l}\text { Nunca he sentido el } \\
\text { impulso de agredir } \\
\text { física o psicológica- } \\
\text { mente a otra persona } \\
\text { por ser homosexual. }\end{array}$ & $\begin{array}{c}\text { El matrimonio entre perso- } \\
\text { nas del mismo sexo garantiza } \\
\text { la igualdad de derechos para } \\
\text { todas las relaciones, indepen- } \\
\text { dientemente de la orienta- } \\
\text { ción sexual }\end{array}$ \\
\hline $\begin{array}{l}\text { Los homosexuales } \\
\text { son capaces de ser } \\
\text { buenos padres o ma- } \\
\text { dres. }\end{array}$ & $\begin{array}{l}\text { La legalización del matrimo- } \\
\text { nio entre personas del mismo } \\
\text { sexo conducirá a cargas } \\
\text { innecesarias, como la seguri- } \\
\text { dad social y los beneficios de } \\
\text { atención médica. }\end{array}$ \\
\hline $\begin{array}{l}\text { La homosexualidad } \\
\text { no es una enferme- } \\
\text { dad psicológica. }\end{array}$ & $\begin{array}{l}\text { Las personas deben tener } \\
\text { la libertad de contraer ma- } \\
\text { trimonio con otra persona, } \\
\text { adultas del mismo sexo, por- } \\
\text { que Dios creó a todas las per- } \\
\text { sonas y no comete errores. }\end{array}$ \\
\hline $\begin{array}{l}\text { Las relaciones homo- } \\
\text { sexuales no son algo } \\
\text { sucio. }\end{array}$ & $\begin{array}{l}\text { El matrimonio entre perso- } \\
\text { nas del mismo sexo conduci- } \\
\text { rá a la decadencia moral de la } \\
\text { sociedad. }\end{array}$ \\
\hline $\begin{array}{l}\text { Las personas homo- } \\
\text { sexuales son iguales a } \\
\text { las heterosexuales. }\end{array}$ & $\begin{array}{c}\text { Me opongo a la legalización } \\
\text { del matrimonio entre perso- } \\
\text { nas del mismo sexo. }\end{array}$ \\
\hline
\end{tabular}

Continúa...

\begin{tabular}{|c|c|}
\hline $\begin{array}{c}\text { Prejuicio hacia los } \\
\text { homosexuales }\end{array}$ & Matrimonio igualitario \\
\hline $\begin{array}{c}\text { Los homosexuales } \\
\text { pueden formar fami- } \\
\text { lias. }\end{array}$ & \\
\hline $\begin{array}{c}\text { No se debe discrimi- } \\
\text { nar a los homosexu- } \\
\text { les solo por el hecho } \\
\text { de serlo. }\end{array}$ & \\
\hline
\end{tabular}

Fuente: Elaboración propia a partir de (Ordóñez, Díaz Velez y Soto Cáceres, 2019; Grigoropoulos y Panos, 2016; Moral de la Rubia y Valle de la O, 2011).

\section{Resultados y discusión}

Los datos sociodemográficos de los participantes se presentan en la Tabla 2, de la cual se desprende que de los 150 sujetos de estudio, el $52.7 \%$ de los encuestados son hombres; de igual manera, el 38\% son personas entre 15 a 25 años; de la muestra el 55.3\%, es decir, 83 encuestados, son solteros; de la misma forma se estableció que 127 de los 150 encuestados son heterosexuales; finalmente, se puntualiza que el 38.7\% tiene nivel de estudios máximo de preparatoria en contraste con el 15.3\% que tiene la primaria como mayor grado de estudios. Por último, cabe destacar que el $81.3 \%$ son originarios del norte del país 
Tabla 2. Perfil de sujetos de estudio

\begin{tabular}{|c|c|c|c|c|c|}
\hline Categoría & $\begin{array}{c}\text { Número de personas } \\
\mathrm{n}=150\end{array}$ & $\%$ & Categoría & $\begin{array}{c}\text { Número de personas } \\
\mathrm{n}=150\end{array}$ & $\%$ \\
\hline Genero & & & Estado civil & \\
\hline Hombre & 79 & 52.7 & Soltero & 83 & 55.3 \\
\hline Mujer & 71 & 47.3 & Casado & 67 & 44.7 \\
\hline Edad & & & Orientación Sexual & & \\
\hline De15 a 25 años & 57 & 38.0 & Homosexual & 16 & 10.7 \\
\hline De 26 a 36 años & 37 & 24.7 & Heterosexual & 127 & 84.7 \\
\hline De 37 a 47 años & 28 & 18.7 & Bisexual & 7 & 4.0 \\
\hline Más de 48 años & 28 & 18.7 & Nivel de estudios & & 15.3 \\
\hline Origen del país & 122 & & Primaria & 23 & 26.7 \\
\hline Norte del país & 18 & 81.3 & Secundaria & 40 & 38.7 \\
\hline Centro del país & 9 & 9 & Preparatoria & 58 & 18.7 \\
\hline Sur del país & & 6.0 & Universidad & 28 & \\
\hline
\end{tabular}

Fuente: Elaboración propia con base en el programa SPSS.

Ahora bien, respecto al estadístico descriptivo de los prejuicios a los homosexuales (ver Tabla 3) se puede señalar que el valor mínimo de respuesta de los encuestados corresponde a 1 y 5 como el puntaje máximo, con un valor de la media de 2.500. Establecido lo anterior, se puede señalar que más de la mitad de los participantes no cuentan con un familiar homosexual en su familia nuclear, como se refleja con el ítem (2), es decir que tiene un valor por debajo de la media de 2.173, pese a esta situación la mayoría de los encuestados acudirían a una fiesta si va una persona homosexual o trabajarían con una de ellas, como lo señalan los ítems (5) con un valor de 4.167 y (6) con un valor de 4.100 respectivamente con un valor por arriba de la media.
De igual manera, es importante señalar que pese a que varios de los participantes acuden de manera frecuente a lugares religiosos, al establecerle un valor de 3.033 por arriba de la media en el ítem (1) hay una mayor aceptación respecto a los derechos de las personas homosexuales en igualdad de los heterosexuales, con un valor sobre la media de 4.213 conforme al ítem (10), además de reconocerse la capacidad de que se formen vínculos estables y duraderos entre los homosexuales ítem (9) con un valor de 3.827 sobre la media.

Alejándose gradualmente de ideas arraigadas, dado que hay más participantes que consideran que los homosexuales son capaces de ser buenas madres o padres, tal como lo establece el ítem (14) con un valor de 3.800; los cuales pueden formar 
Tabla 3. Estadístico descriptivo prejuicio hacia personas homosexuales $n=150$

\begin{tabular}{|c|c|c|c|c|}
\hline Ítem & Mínimo & Máximo & Media & $\begin{array}{l}\text { Desviación } \\
\text { estándar }\end{array}$ \\
\hline $\begin{array}{l}\text { Acostumbro a asistir de manera frecuente a algún culto, adoración, } \\
\text { misa, etc. }\end{array}$ & 1.0 & 5.0 & 3.033 & 1.5475 \\
\hline En mi familia cercana hay homosexuales. & 1.0 & 5.0 & 2.173 & 1.4225 \\
\hline En mi familia amplia hay homosexuales (tíos, tías, primos, primas). & 1.0 & 5.0 & 2.960 & 1.5923 \\
\hline En mi grupo de amigos, laboral o académico, hay homosexuales. & 1.0 & 5.0 & 3.527 & 1.4732 \\
\hline Asistiría a una fiesta si supiera que va a ir un homosexual. & 1.0 & 5.0 & 4.167 & .9653 \\
\hline Trabajaría con un homosexual. & 1.0 & 5.0 & 4.100 & 1.1097 \\
\hline No me molesta la idea de tener amigos homosexuales. & 1.0 & 5.0 & 4.213 & 1.0271 \\
\hline $\begin{array}{l}\text { Los homosexuales que viven en pareja deberían tener el derecho de } \\
\text { adoptar niños. }\end{array}$ & 1.0 & 5.0 & 3.147 & 1.5034 \\
\hline $\begin{array}{l}\text { Los homosexuales son capaces de tener vínculos amorosos tan estables } \\
\qquad y \text { duraderos como las parejas heterosexuales. }\end{array}$ & 1.0 & 5.0 & 3.827 & 1.2192 \\
\hline $\begin{array}{l}\text { Las personas homosexuales tienen los mismos derechos que las } \\
\text { personas heterosexuales. }\end{array}$ & 1.0 & 5.0 & 4.213 & .9018 \\
\hline Me incomoda si dos hombres se toman de la mano. & 1.0 & 5.0 & 2.353 & 1.3861 \\
\hline Pienso que se debe respetar al colectivo homosexual. & 1.0 & 5.0 & 4.113 & 1.0333 \\
\hline $\begin{array}{l}\text { Nunca he sentido el impulso de agredir física o psicológicamente a otra } \\
\text { persona por ser homosexual. }\end{array}$ & 1.0 & 5.0 & 3.373 & 1.7438 \\
\hline Los homosexuales son capaces de ser buenos padres o madres. & 1.0 & 5.0 & 3.800 & 1.1758 \\
\hline La homosexualidad no es una enfermedad psicológica. & 1.0 & 5.0 & 3.793 & 1.3917 \\
\hline Las relaciones homosexuales no son algo sucio. & 1.0 & 5.0 & 3.580 & 1.5469 \\
\hline Las personas homosexuales son iguales a las heterosexuales. & 1.0 & 5.0 & 3.933 & 1.3594 \\
\hline Los homosexuales pueden formar familias. & 1.0 & 5.0 & 3.680 & 1.3427 \\
\hline No se debe discriminar a los homosexuales solo por el hecho de serlo. & 1.0 & 5.0 & 4.233 & 1.0645 \\
\hline
\end{tabular}

Fuente: Elaboración propia con base en el programa SPSS.

familias según el ítem (18) con un valor de 3.680; merecedores de respeto ítem (12) con un valor de 4.113 y a las cuales no se les debe de discriminar por el solo hecho de ser homosexuales conforme al ítem (19) con un valor arriba de la media de 4.233. Pese a lo establecido, en un tópico más específico como la adopción para parejas homosexuales, si bien no se detona una negativa total respecto al tema referido, la aceptación por parte de los participantes no es tan elevada como en otros temas, al señalarse un valor de 3.147 por arriba de la media en el ítem (8).

Respecto al estadístico descriptivo de los matrimonios igualitarios (ver Tabla 4), se puede establecer que el valor mínimo de respuesta de los encuestados corresponde 
a 1 y el máximo a 5, con una media de 2.500, utilizando el mismo programa; y de las respuestas recabadas se desprende como dato relevante que en el item (22), con un valor por arriba de la media de 3.447, los participantes consideran que dos personas del mismo sexo pueden proporcionar la misma calidad y confianza que una pareja de diverso sexo y, en concordancia con esta premisa, los encuestados manifiestan que tienen derecho a acceder a una figura que les dé una estabilidad a su relación amorosa, siendo un propósito del matrimonio, tal y como señala el ítem (23), con un valor por arriba de la media de 3.507. Esta información se ve robustecida con una alza sobre la media en los items (25), con un valor de 3.960 y en él (26), con un valor de 3.440; los participantes reflejan respectivamente en cada ítem una mayor conformidad para que las personas homosexuales accedan a seguridad social y atención médica, de igual manera, se establece que el matrimonio igualitario mejorará la moral de la sociedad al promover la igualdad; finalmente, hay un tendencia en apoyar a personas no heterosexuales a buscar el derecho al matrimonio, como se señala en el ítem (27) con un valor de 3.600 .

En congruencia a lo señalado, la legalización del matrimonio igualitario es un paso importante para la aceptación de personas que no son heterosexuales, como lo señala el ítem (30), con un valor de 3.660 por arriba de la media; de igual manera el ítem (32) con un valor de 3.507 sobre la media, los participantes consideran que el matrimonio igualitario garantizará la igualdad de derechos en todas las parejas, sin importar la orientación sexual.

En diversos ítems, pese a que deben interpretarse a contrario sensu, los resultados son menos progresistas, por ejemplo, el ítem (21) con un valor de 2.987, es decir, un .487 por arriba de la media, se señala que el matrimonio igualitario no le quitará fuerza moral a la institución de la familia, sin embargo, solo el $23.3 \%$ de los encuestados están totalmente de acuerdo a diferencia del restante $77.7 \%$; diverso ejemplo se encuentra en el item (24) con un valor de 2.567, el cual señala que el matrimonio igualitario generaría que se enseñará con normalidad la homosexualidad en las escuelas, atacando, a su vez, a la sociedad, del cual solo el $36 \%$ está totalmente en desacuerdo con dichas suposiciones. En el mismo orden de ideas, se señala que el hombre y la mujer se complementan naturalmente a diferencia de la parejas homosexuales, por lo que no debería permitirse, lo anterior mediante el ítem (29) con un valor de 2.473, en el cual hay una tendencia que va de la indiferencia a la aceptación a dicha premisa de un 47.9\%; finalmente el ítem (31) señala que la crianza de los hijos es uno de los propósitos principales del matrimonio, lo que de manera preliminar generaría una clara contradicción entre los primeros ítems señalados. 
Tabla 4. Estadístico Descriptivo matrimonio igualitario $n=150$

\begin{tabular}{|c|c|c|c|c|}
\hline Ittem & Mínimo & Máximo & Media & $\begin{array}{l}\text { Desviación } \\
\text { estándar }\end{array}$ \\
\hline El matrimonio no debe ser exclusivo para los heterosexuales. & 1.0 & 5.0 & 3.420 & 1.6396 \\
\hline $\begin{array}{l}\text { El matrimonio entre personas del mismo sexo socava el significado de } \\
\text { la familia tradicional. }\end{array}$ & 1.0 & 5.0 & 2.987 & 1.4423 \\
\hline $\begin{array}{l}\text { Dos padres amorosos del mismo sexo pueden proporcionar la misma } \\
\text { calidad de crianza y orientación como hombre y mujer. }\end{array}$ & 1.0 & 5.0 & 3.447 & 1.4168 \\
\hline $\begin{array}{c}\text { Un propósito principal del matrimonio es proporcionar estabilidad } \\
\text { en una relación amorosa. Las parejas del mismo sexo deben tener este } \\
\text { derecho legal a su disposición. }\end{array}$ & 1.0 & 5.0 & 3.507 & 1.3939 \\
\hline $\begin{array}{l}\text { El reconocimiento del matrimonio entre personas del mismo sexo } \\
\text { representa una amenaza para la sociedad porque las escuelas se verán } \\
\text { obligadas a enseñar que la homosexualidad es normal. }\end{array}$ & 1.0 & 5.0 & 2.567 & 1.5124 \\
\hline $\begin{array}{l}\text { La protección matrimonial, como la seguridad social y los beneficios de } \\
\text { atención médica, debe estar disponible para parejas del mismo sexo. }\end{array}$ & 1.0 & 5.0 & 3.960 & 1.0984 \\
\hline $\begin{array}{l}\text { El matrimonio entre personas del mismo sexo fortalecerá la moral de la } \\
\text { sociedad al apoyar la igualdad. }\end{array}$ & 1.0 & 5.0 & 3.440 & 1.3732 \\
\hline $\begin{array}{l}\text { Apoyo a personas que no son heterosexuales que buscan derechos de } \\
\text { matrimonio. }\end{array}$ & 1.0 & 5.0 & 3.600 & 1.3108 \\
\hline $\begin{array}{l}\text { Debido a que más personas tendrán los beneficios del matrimonio, la } \\
\text { familia será fortalecida por el reconocimiento de los matrimonios del } \\
\text { mismo sexo. }\end{array}$ & 1.0 & 5.0 & 3.513 & 1.3448 \\
\hline $\begin{array}{l}\text { Hombres y mujeres se complementan naturalmente, por lo tanto, una } \\
\text { unión entre dos hombres o dos mujeres no deben ser reconocidas en el } \\
\text { matrimonio. }\end{array}$ & 1.0 & 5.0 & 2.473 & 1.4778 \\
\hline $\begin{array}{l}\text { La legalización del matrimonio de personas del mismo sexo es un paso } \\
\text { importante hacia la aceptación de personas que no son heterosexuales. }\end{array}$ & 1.0 & 5.0 & 3.660 & 1.2944 \\
\hline $\begin{array}{c}\text { Un propósito principal del matrimonio es criar hijos, por lo tanto, solo } \\
\text { un hombre y una mujer debería estar casados. }\end{array}$ & 1.0 & 5.0 & 2.387 & 1.4367 \\
\hline $\begin{array}{l}\text { El matrimonio entre personas del mismo sexo garantiza la igualdad de } \\
\text { derechos para todas las relaciones, independientemente de la orienta- } \\
\text { ción sexual. }\end{array}$ & 1.0 & 5.0 & 3.507 & 1.3248 \\
\hline $\begin{array}{l}\text { La legalización del matrimonio entre personas del mismo sexo condu- } \\
\text { cirá a cargas innecesarias, como la seguridad social y los beneficios de } \\
\text { atención médica. }\end{array}$ & 1.0 & 5.0 & 2.307 & 1.2037 \\
\hline $\begin{array}{l}\text { Las personas deben tener la libertad de contraer matrimonio con otra } \\
\text { persona, adultas del mismo sexo porque Dios creó a todas las personas } \\
\text { y no comete errores. }\end{array}$ & 1.0 & 5.0 & 3.027 & 1.4092 \\
\hline $\begin{array}{l}\text { El matrimonio entre personas del mismo sexo conducirá a la decaden- } \\
\text { cia moral de la sociedad. }\end{array}$ & 1.0 & 5.0 & 2.453 & 1.4264 \\
\hline $\begin{array}{c}\text { Me opongo a la legalización del matrimonio entre personas del mismo } \\
\text { sexo. }\end{array}$ & 1.0 & 5.0 & 2.120 & 1.4280 \\
\hline
\end{tabular}

Fuente: Elaboración propia con base en el programa SPSS. 


\section{Conclusión}

A lo largo de cinco décadas, el derecho como constructo social ha evolucionado para abarcar a la sociedad en la actualidad, también es cierto que está clara oposición de las coaliciones civiles, religiosas y políticas han impedido el avance sistemático de leyes que otorguen el reconocimiento de instituciones como el matrimonio para cualquier persona; un claro ejemplo es el acontecido en la Ciudad de México, puesto que mientras la asamblea de dicha entidad aprobó una modificación al Código Civil para quitar la limitante de "unión entre hombre y mujer" para quedar como la "unión de personas" en el año 2009; fue en el año 2016, ante la presentación de la propuesta de reforma constitucional del presidente Enrique Peña Nieto, que la clara oposición de grupos profamilia y provida, generaron una presión político-social que tuvo como respuesta la falta de apoyo y, a su vez, el abandono de dichas propuestas. A la fecha un largo camino se ha recorrido, entre leyes y reformas que han reconocido el matrimonio igualitario en varios estados del país, pero en otros, inclusive en votaciones del año 2020, los grupos de puntos constitucionales han impedido por abstención o votos en contra las modificaciones a los códigos familiares de sus respectivos estados, siendo el caso, entre otros, el de Baja California, Zacatecas y Sonora.
Mediante el presente estudio se puntualizan los principales tópicos utilizados por los grupos opositores (religiosos, políticos y miembros de la sociedad profamilia) para establecer si las consignas que refieren como un clamor social son representativas para la sociedad juarense y si estas infringen algún tipo de presión política. De los resultados obtenidos mediante los instrumentos, se determinó una baja en temas de discriminación respecto a diversos estudios, mientras que la aceptación a grupos homosexuales que tiene igualdad de derechos que los heterosexuales subió, puesto que inclusive 72 de los entrevistados que, se traducen en el $48.0 \%$, sí convivirían con homosexuales, mientras que solo el 2.0\%, es decir, 3 personas, no lo harían, aunado a que 74 personas sí trabajarían con personas homosexuales y solo 6 no lo harían, es decir, $49.3 \%$ contra el $4.0 \%$ respectivamente.

No solo se percibe una serie de prejuicios disminuidos, sino que son significativamente menores en comparación con los que sí están conformes al reconocimiento de derechos, por ejemplo, solo 4 encuestados de los 150 consideran que los homosexuales no tienen los mismos derechos que las personas heterosexuales, es decir, del 100\% de los entrevistados solo el $2.7 \%$ presentan una reticencia tan marcada; aunado a esto, el $52 \%$ de los participantes refirieron que no se incomodan al ver a dos hombres tomados de las manos. Esta 
disminución de la reticencia de la población a los temas de igualdad y equidad de derechos se puede asociar a la visualización de los derechos humanos, puesto que, de manera constante a lo largo de las últimas décadas, son temas que captan la atención social, a tal grado que ya existe un sistema de inclusión y respeto al colectivo LGBTTTIQ, tal y como lo señala el ítem (12) con una respuesta favorable del $69 \%$. La tendencia anteriormente descrita, señala que hay una correspondencia en la disminución de prejuicios y el aumento de las relaciones sociales que los participantes tienen con personas homosexuales, puesto que se sensibiliza al tener una interacción mayor.

Ahora bien, no debe confundirse este aumento de conformidad con una aceptación total de la muestra respecto de los derechos que les corresponden a las personas homosexuales. Como punto de partida se clarifica que, si bien es cierto muchos de los tópicos van al alza, aún existe un elevado nivel de indecisión y de indiferencia para reconocer que las personas homosexuales tienen los mismos derechos que las personas heterosexuales; tales como poder adoptar, poder formar familias no tradicionales y máxime que estas familias puedan socavar la concepción tradicional de estas figuras jurídicas. De todos y cada uno de dichos ejemplos, se desprende una ventana de oportunidad, tanto para las personas que están en favor, como aque- llas que están en contra del matrimonio igualitario, dado que, mediante la realización de marchas, protestas, manifestaciones, ese gran porcentaje de personas que no se encuentran en los extremos de los valores de la escala podrían tomar, modificar o reafirmar sus posturas respecto a esté tan debatido tema, causando un mayor impacto en las esferas políticas encargadas de la creación de leyes; pero también es una oportunidad clara para el gobierno de impartir información de carácter nacional e internacional donde se establezca el concepto de derechos humanos y los alcances que estos tienen, lo que influye positivamente en la disminución de los prejuicios sociales y genera una mayor apertura para la igualdad.

No se deja de lado que para la religión el matrimonio es una institución inalterable, con la cual se logra un acercamiento a Dios y cuya finalidad es la procreación y perpetuación de la especie humana que solo se logra entre un hombre y una mujer, por lo menos en las religiones tocadas en el presente trabajo. La religión forma parte de la sociedad y las enseñanzas eclesiásticas fijan el punto de anclaje para muchos miembros de la sociedad, estableciendo definiciones ancestrales que no han mutado a lo largo del tiempo y que se arraigan generación tras generación, por lo que separar las creencias religiosas de las normas legales que rigen a la sociedad y reconocen los derechos humanos re- 
quiere de un trabajo constante, progresivo y con una estructura que permita separar ambos sectores. No se plantea la desmotivación de las prácticas religiosas, solo se señala que es una ventana para trabajar en la población.

Finalmente, el presente trabajo abre una puerta de oportunidad y de relevancia para analizar la forma en la cual los partidos políticos seleccionan a sus representantes para competir en campañas electorales y para establecer las propuestas de campaña que cada uno tiene; cómo se refirió la opinión de la sociedad en temas relacionados con derechos humanos impulsa o frena los objetivos políticos y a mayor aceptación, mayor apertura política, contrario a lo que pasa en la actualidad con diversos actores políticos quienes tienen una postura religiosa marcada, a tal grado que en el PES (el cual existe aún como partido político estatal) diversos miembros realizan una intervención en las comunidades religiosas y no solo se limitan a su círculo cercano, sino que también mediante sus intervenciones extiende su mensaje político al resto de sus compañeros. Y lo que, aunado a un reclamo social como medio de coerción, sí impacta e influye en las votaciones de los legisladores, tal y como aconteció en las reformas constitucionales propuestas por el presidente Peña Nieto en el 2016. Establecer políticas públicas generadas por el gobierno, que sean correctamente estructuradas y aplicadas podría cambiar los paradigmas sociales y religiosos que impactan en la sociedad, siendo el presente trabajo una referencia para futuras investigaciones que profundicen en el tema.

\section{Referencias}

Arlettaz, F. (2015). Matrimonio homosexual y sexularización (1. a ed.). (P. Salazar Ugarte y P. Capdevielle, Eds.). Instituto de Investigacion Juridica de la UNAM.

Bemheim, C. T. (1997). Los derechos humanos: evolucion historica y reto educativo (2. ${ }^{a}$ ed.). UNESCO.

Bustillos, J. (2011). Derechos humanos y protección constitucional: Breve estudio sobre el matrimonio entre personas del mismo sexo en México y en perspectiva comparada. Boletín Mexicano de Derecho Comparado, 44(132), 1017-1045.

Cabrera Priego, P. (2016). Evolución legal de los matrimonios homosexuales en México. (M. R. Falcón, ed.) Revista Electrónica Ecos Sociales, 173-182. http://revistas.ujat.mx/index. php/ecosoc/article/view/1247

Calvo Caravaca, A. L., y Carrascosa González, J. (2009). Derecho internacional privado y matrimonio entre personas del mismo sexo. Anales del Derecho, 23, 11-70. https://revistas. um.es/analesderecho/article/view/56411

Casquete, J. (2005). Manifestacion e identidad colectiva. Revista Internacional de Sociología. (CSIC, ed.). 63, 103-125. doi:https://doi. org/10.3989/ris.2005.i42.198 
Chavez, V. (19 de mayo de 2016). Encuentro Social rechaza PES matrimonios gays. El Financiero. https://www.elfinanciero.com.mx/ nacional/encuentro-social-rechaza-pes-matrimonios-gays

Congreso de la Unión. (2016). Comision vota en contra dictamen que proponia matrimonio igualitario. Camara de Diputados, Comunicación Social. http://www5.diputados.gob. $\mathrm{mx} /$ index.php/esl/Comunicacion/Boletines/2016/Noviembre/09/2517-Comision-vota-en-contra-dictamen-que-proponia-matrimonio-igualitario

Corte IDH, Opinion Consultiva OC- 24/17 (Corte Interamericana de Derechos Humanos, 24 de noviembre de 2017). https://www.corteidh.or.cr/opiniones_consultivas.cfm

El papa respalda oposición a los matrimonios igualitarios en México (25 de septiembre de 2016). Excelsior. https://www.excelsior.com. $\mathrm{mx} /$ nacional/2016/09/25/1118915\#view-1

Finnis, J. M. (1994). Derecho, moral y orientacion sexual. Notre Dame Law Review, 69(5), 583-620. https://dadun.unav.edu/bitstream/10171/14112/1/PD_41-2_25.pdf

Flores, G. (1995). Matrimonio y Familia.Biblioteca de Autores Cristianos.

Gimero, B., y Barrientos, V. (2009). La institución del matrimonio después del matrimonio homosexual. Íconos. Revista de Ciencias Sociales, 13(35), 19-30. doi:10.17141/ iconos.35.2009.379

Girgis, S., George, R. P., y Anderson, R. T. (2020). ¿Qué es el matrimonio? Ius Humani,
Revista de Derecho, 9, 87-137. doi:https://doi. org/10.31207/ih.v9i1.226

Gomez-Lugo, F. y Madrigal-Borloz, V. (2018). El 2016: un año marcado por significativos avances, violencia y actores anti -derechos. ILGA. https://ilga.org/es/America-situaci\%C3\%B3n-personas-lesbianas-gay-bisexuales-2016-ILGA_homofobia-estado

González Pérez, M. (2007). La representación social de las familias diversas: Ley de Sociedades de Convivencia. El Cotidiano, 22(146), 21-31. doi:ISSN: 0186-1840

Grigoropoulos, I., y Panos, K. (2016). Reliability and Validity of the Greek Translation of. Journal of GLBT Family Studies, 1-12. doi:10.10 80/1550428X.2015.1080133

Hernández Sampieri, R., Fernández Collado, C., y Baptista Lucio, P. (2010). Metodología de la Investigación. En R. Hernández Sampieri, C. Fernández Collado, P. Baptista Lucio, \& J. M. Chacón (Ed.), Metodología de la Investigación (5. ${ }^{a}$ ed., pp. 5-19). McGraw-Hill. https:// www.esup.edu.pe/descargas/dep_investigacion/Metodologia\%20de\%20la\%20investigaci\%C3\%B3n\%205ta\%20Edici\%C3\%B3n.pdf Instituto Nacional de Estadistica y Geografia (17 de Septiembre de 2020). Chihuahua [indicador sociodemográfico] https://www.inegi. org.mx/app/areasgeograficas/?ag=08

Llama la Iglesia a castigar en las urnas a partidos que "atentan" contra la fe (17 de agosto de 2010). La Jornada. https://www.jornada. com.mx/2010/08/17/politica/004n1pol

Lopez, J. A. (2017). Movilización y contramovilización frente a los derechos LGBTI. Res- 
puestas conservadoras al reconocimiento de los derechos humanos. Estudios Sociológicos de El Colegio de México, XXXVI(106), 161187. doi:10.24201/ES.2018V36N106.1576

Lo que va de la lucha LGBT+ durante el 2020 en México (2 de octubre de 2020). Notipress. https://notipress.mx/actualidad/lo-que-vade-la-lucha-lgbt-en-2020-3041

Martínez Aguayo, M. A. (2009). Investigación historiográfica sobre la lucha a favor de la no discriminación, la inclusión social y el reconocimiento y aceptación de la pluralidad. Consejo Nacional para Prevenir la Discriminación, Direccion General Adjunta de Estudios, Legislación y Políticas Públicas, Consejo Nacional para Prevenir la Discriminación. http:// www.conapred.org.mx/documentos_cedoc/ E07-2009[1]r.pdf

Martínez, S. (01 de agosto de 2016). El ano, según el cardenal Norberto Rivera. Sinembargo. https://www.sinembargo.mx/01-082016/3074174

Moral de la Rubia, J., y Martínez Sulvarán, J. (2011). Escala de actitud hacia la homosexualidad: propiedades psicométricas y aspectos diferenciales por sexo. Revista Internacional de Ciencias SOciales y Humanidades SOCIOTAM, XXI(1), 105-124. doi:ISSN: 1405-3543

Moral de la Rubia, J., y Valle de la O, A. (2011). Escala de actitudes hacia lesbianas y hombres homosexuales (ATLG). Nova Scientia, 4(7), 153-171. doi:E-ISSN: 2007-0705

Ordóñez , J. A., Diaz Velez, C., y Soto Cáceres, V. (2019). Adaptación de una escala para medir actitud hacia el matrimonio y unión civil gay en población de Chiclayo, Perú. Revista del Cuerpo Médico del HNAAA, 9(3), 189-191. doi:http://cmhnaaa.org.pe/ojs/index.php/ rcmhnaaa/article/view/117

Para López Obrador, legalizar el aborto y el matrimonio gay no es algo "tan importante". (12 de junio de 2015). Animal Politico. https:// www.animalpolitico.com/2015/06/para-lopez-obrador-legalizar-el-aborto-y-el-matrimonio-gay-no-es-algo-tan-importante/

Quintana Osuna, K. (2017). La evolucion juridica del matrimonio igualitatrio en Mexico, $\mathrm{Su}$ impacto en el reconocimiento de derechos. Revista del Centro de Estudios Constitucionales SCJN, 21-54.

Ramon Mendos, L. (2019). Homofobia del Estado. (J. F. Marreque, Ed.). ILGA. https://ilga. org/downloads/ILGA_World_Homofobia_ de_Estado_Actualizacion_Panorama_global_Legislacion_diciembre_2019.pdf

Rivera, A. (01 de agosto de 2016). Matrimonio gay daña espíritu. EL Universal. https:// www.elmundo.es/sociedad/2016/09/13/57d7d889268e3ed5128b4584.html

Rodríguez Castro, Y., Lameiras-Fernández, M., Carrera Fernández, V., y Vallejo Medina, V. (2013). Validacion de la Escala de Homofobia Moderna en una muestra de adolescentes. Anales de Psicología, 29(2), 523-533.

Salinas Hernández, H. (2017). Matrimonio igualitario en México: la pugna por el Estado laico y la igualdad de derechos. El Cotidiano, 95-104.

Sánchez, J. A. (2017). El matrimonio igualitario en México: una aproximación contextual 
desde las prácticas sociopolíticas hacia las iniciativas de ley. Ciudades, Estados y Política, 4(3), 87-101. doi:http://dx.doi.org/10.15446/cep Serrato Guzmán , A. N., y López Sánchez, E. (2018). Del coming out a los derechos humanos en las demandas de las organizaciones de la sociedad civil del movimiento LGBT: estrategias discursivas de refugio. 15, 119-114. doi:10.29092/uacm.v15i37.633

Siscar, M. (15 de julio de 2014). Partido Encuentro Social, a favor de las familias tradicionales y contra el aborto. Animal Politico. https://www.animalpolitico.com/2014/07/ partido-encuentro-social-favor-de-las-familias-tradicionales-y-contra-el-aborto/

Soriano Martínez, E. (2011). EL matrimonio homosexual en Europa. Iuris Tantum Revista Boliviana de Derecho, 204-216. doi: ISSN: 2070-8157
Suprema Corte de Justicia de la Nación. (Diciembre de 2010). Semanario Judicial de la Federación. https://sjf.scjn.gob.mx/sjfsist/paginas/DetalleGeneralScroll.aspx?id=22553\&Clase $=$ DetalleTesisEjecutorias $\& I d T e=161268$

Toro-Alfonso, J. (2012). El estado actual de la investigación sobre la discriminación sexual. Terapia Psicológica, 30(2), 71-76. doi:10.4067/ S0718

Torres Falcon, M. (2009). Sexualidades minoritarias y derechos humanos. El caso de las sociedades de convivencia en el Distrito Federal. Revista Sociológica, 24(69), 157-182.

Varsi Rospigliosi, E. (2011). Tratado de Derecho de Familia Matrimonio y uniones estables Tomo II (2. ${ }^{a}$ ed., Vol. 2 ). Gaceta Jurdica S.A. http://repositorio.ulima.edu.pe/handle/uli$\mathrm{ma} / 5231$ 